\title{
Reflexiones de una trabajadora social académica
}

Me he tomado este acto de presentación del libro, Epistemología del Trabajo Social. De la evidencia empírica a la exigencia teórica, como si fuera una clase, tal vez porque este curso no he dado ninguna en la Facultad, y siento "mono" del encuentro que me proporciona este escenario. Sí, lo tengo, queridas alumnas, colegas docentes y profesionales, queridas todas. Muchas gracias por hacerme revivir de vez en cuando la pasión que me sostuvo tanto tiempo.

Quiero dar las gracias también a quienes me han ayudado en la finalización del libro: empezaré por Teresa $\mathrm{G}^{\mathrm{a}}$ Giráldez, quien ha participado con entusiasmo en muchos momentos de su confección; a Aurora Castillo por sus minuciosas correcciones; y a Carmen $\mathrm{M}^{\mathrm{a}}$ Roncal porque, como siempre, su ayuda es incalculable para mí al hacerse cargo de la configuración informática de la obra para su entrega a la editorial. De la misma manera, deseo agradecer a Ediciones Complutense su publicación, así como a Maite García por su ayuda en el pesado momento final.

Pues bien, este libro ha nacido del deseo de otro, Luis Nogués, él, como digo en la introducción, me ayudó a burlar a la nostalgia que se instaló en mí tras la jubilación. Luis me pidió hace tiempo que escribiera sobre la esencia del trabajo social, pero a lo más que llegué fue a abrir una carpeta. No daba con las palabras que me ayudaran a adentrarme en un río tan lleno de meandros, de bifurcaciones, de idas y venidas tan lentas unas veces $\mathrm{o}$, más rápidas otras, como las que transcurren por la modernidad líquida. Me ha sido imposible tratar de atrapar la esencia por más vueltas que haya podido darle que, tampoco fueron tantas, ya que no soy esencialista, más bien, por jugar con la palabra de la filosofía, sí soy existencialista. Y es porque me interesa la vida más que la esencia de las cosas, me interesa el devenir, el existir. Por eso, porque existo, pienso en los procesos, en las coyunturas, en las circunstancias, en los fenómenos sociales; y el trabajo social está sujeto a todas las situaciones sociales e históricas que lo han atravesado y condicionado en sus contenidos. Por todo eso me dejé ir viviendo lo bastante cerca de las profesionales con las que mantengo contacto hoy, en especial, el Foro de Servicios Sociales de Madrid, en el que me han integrado a pesar de mi edad, y en el que encuentro un lugar de dialéctica que ampara mi discurrir.

En este transcurso, un buen día, después de una clase, Luis materializó su demanda. Me pidió que hiciera algo con mi obra, me lo dijo más o menos así, no recuerdo con exactitud, pero el caso es que se prendió la mecha entre los dos y he aquí la llama que nos congrega, una recopilación de parte de mis trabajos.

Comenzaré por decir algunas palabras sobre el afán que ha perseguido mi pensamiento en trabajo social y en la vida en general, esto es: la unidad de los opuestos. En el proceso de la construcción de mis reflexiones sobre el mundo de la vida me he sentido siempre cerca del pensamiento oriental, tal vez desde mis inicios en la práctica del Zen hace muchos años, a la par que me formaba en la dialéctica, el psicoanálisis o la sistémica. Hoy podemos encontrar confluencias en muchos pensadores europeos con el pensamiento oriental. Para no entrar en citas largas, solo traeré a Morin, por el lado de la sociología y a Haruki Murakami por la literatura. Pero no quiero centrarme en Morin puesto que a él se le puede encontrar en este libro, en cambio, en una de las novelas de Murakami, Los años de peregrinación del chico sin color, he hallado lo que quiero expresar. Leo:

En ese momento, por fin lo captó. En lo más profundo de sí mismo, Tsukuru Tazaki lo comprendió: los corazones humanos no se unen sólo mediante la armonía. Se unen, más bien, herida con herida. Dolor con dolor. Fragilidad con fragilidad. No existe silencio sin un grito desgarrador, no existe perdón sin que se derrame sangre, no existe aceptación sin pasar por un intenso 
sentimiento de pérdida. Esos son los crímenes de la verdadera armonía.

He aquí en la literatura lo que quería decir: mi afán por hallar el sentido de la vida en la unidad de los opuestos que, en las palabras de Murakami lo encontramos en la última frase llena de una rotundidad solemne: Esos son los crimenes de la verdadera armonía. ¿Es concebible una armonía con crímenes? ¿No son conceptos diametralmente opuestos? Solo en sus apariencias, pero no nos quedemos ahí fijados.

En nuestra disciplina, puedo conseguir la unidad observando el mundo no en su polaridad, no en su dicotomía, no en el bien, que siempre se nos representa como algo que está en uno mismo y el mal afuera (generalmente, si miramos desde nuestro campo visual, el mal está en el sistema o en lo incapaces que son los políticos). Porque es fácil caer en la creencia que señala que "si esto, lo que yo pienso, es lo bueno, lo otro, lo que piensan los otros es malo, y viceversa". Y, todo hay que decirlo, generalmente, nosotras, las trabajadoras sociales, nos sentimos en el lado de los buenos, los que dictamos y juzgamos la conducta de los demás, error garrafal del que hemos de desprendernos con esfuerzo de reflexión autocrítica y con formación en otros paradigmas. Es el maniqueísmo tan bien instalado en nuestra tradición judeocristiana que nos envuelve y que en trabajo social ha tomado un peso cognitivo muy importante, aunque no es la única disciplina que se traba en esa creencia. Es un problema de nuestra cultura, y más hoy, instalados como estamos en la polarización política, en los extremos, o en la radicalización de posturas enfrentadas.

Salir de ese huerto cercado por el pensamiento dicotómico, es uno de los deseos más profundos que me afanan hoy en día. Transitar por "Esa llanura inmensa que a todo da vida", título de una pequeña obra de poesía de mi hermano Fernando, es lo que da sentido a mi existencia cotidiana en la reflexión del encuentro con los demás, con las instituciones y con la vida. En esa búsqueda es donde puedo discurrir por el lecho de un río que funde sus aguas yendo a la mar, ahora ya lentamente después de la bravura de la juventud. Pero necesitaré siempre la bravura de la juventud, por eso me siento tan bien en El Foro.

Mas os preguntaréis qué sentido tiene esta cosmovisión. A mí, saber que el mundo se comporta así me sitúa en una posición en la que la indignación por los conflictos que no podemos resolver adquiere matices diferentes. $\mathrm{Y}$ en trabajo social pienso que es importante ir alejándose cada vez más de las posiciones salvadoras que han impregnado nuestro actuar durante mucho tiempo para estudiar una metodología de intervención más pragmática que contenga la evaluación como proceso del proyecto, así como la supervisión como elemento de investigación.

En este punto tendría que pararme a reflexionar sobre qué estamos haciendo con la formación de los futuros profesionales pero no hay tiempo ahora para eso. Sin embargo, sí quiero lanzar algunas preguntas a los docentes para que resuenen en estas paredes.

- ¿Cómo salir de las verdades absolutas que nos llevan a caminos trazados por esquemas preconcebidos que ya no sirven para analizar el mundo de hoy?

- ¿Cómo formar a las alumnas en las paradojas, en la incertidumbre y en la complejidad de nuestro multiverso? Referido a Mary Richmond, Alfonsa Rodríguez concibió un magnífico artículo al que me sumó, llamado: "El pensamiento complejo de M. Richmond: algo más que una ventana al pasado".

- ¿Cómo dotar al campo profesional de herramientas analíticas y de intervención más pragmáticas y evaluables, para no seguir cayendo en el idealismo en el que se les ha formado hasta ahora, con viejos esquemas como el de ser agentes de cambio o la definición de Melbourne que habla de la liberación de las personas?

- ¿Cómo se forman los docentes para, a su vez, formar a los alumnos en una nueva mirada al mundo de la vida que tenga en cuenta los elementos señalados en esas preguntas?

En realidad, me doy cuenta, de que he ido por otro camino sobre los pasos del libro. Comencé hace años, lo que es hoy el primer capítulo, con la comprensión de cómo el orden y el desorden se hostigan a lo largo de la historia en esa inextricable unión en la que no se gana, sino que se perpetúa la dinámica hasta parecernos a veces inalcanzable la posibilidad de reconstruir la historia en pos de un futuro de mayor igualdad, mayor distribución de la riqueza y justicia social que, sentimos, no podemos 
aplazar más. Lo intentamos una y miles de veces pero las soluciones que hay en nuestra mano en esta sociedad, cada vez más neoliberal, se alejan con frustración de nuestras posibilidades. Hay fuerzas políticas que nos superan hoy más que nunca a pesar de nuestro pretendido progreso y no podemos transformar las estructuras del sistema como se ha venido repitiendo en la profesión. Sin embargo, siendo realistas, sí podemos contribuir junto con otras profesiones, y de hecho se hace en muchos centros tanto de asistencia primaria como especializada, a transformar determinados itinerarios individuales y familiares.

$Y$ para ir terminando quiero aclarar antes algunos contenidos que se encuentran en la recopilación del libro. Lo primero he de advertir que esta perspectiva epistemológica que anhelo para mi vida no me sitúa en la neutralidad política, más al contrario, puedo elegir mis opciones de resistencia ante la marea neoliberal. De ahí que la concepción del objeto de la disciplina, el malestar psicosocial, en el segundo capítulo, me haya llevado a optar en mi formación por los tres principales modelos teóricos que podrían, desde mi punto de vista, explicar más ampliamente los problemas sociales que tratamos de resolver, el psicoanálisis, la dialéctica y la sistémica. Estas perspectivas se encuentran en el tercer capítulo de la primera parte. Termina esta con unas reflexiones sobre el saber y el poder en trabajo social en las que se abordan los vacíos de conocimiento que tiene la disciplina y cómo, siempre desde mi punto de vista, es posible llenarlos.

La segunda parte está dedicada a la epistemología de la intervención, siempre que esta no se entienda en su vertiente puramente práctica; es decir, primera y segunda parte forman un todo del que es imposible separar la parte teórica de la práctica, postura muy común en trabajo social por aquello de concebir el mundo en su fragmentación, como ya señalé antes.

En el capítulo quinto con el que se abre esta segunda parte, se profundiza sobre el concepto de modelo desde una perspectiva operativa. En ese sentido, me pregunto si esa concepción sirve a la necesaria labor de investigación, ausente por el momento en España. Y es en el concepto de proyecto donde pongo el acento para investigar y dar cuenta a la comunidad científica de nuestra producción en la aplicación de teorías de tercer nivel. El contenido del sexto capítulo trata sobre las relaciones de poder en los encuentros profesionales, una cuestión éti- ca de primer orden. La dominación burocrática en el sentido weberiano, como marco para las relaciones de poder, el concepto de voluntad de poder en Nietzsche y la práctica del cuidado de uno mismo de Foucault completan estas reflexiones.

El séptimo capítulo de esta obra lo escribí hace mucho tiempo en momentos en que el dar recursos había sustituido a una relación fundamentada en un trabajo social en el que yo me había formado y que sí daba sentido a la profesión, el encuentro entre profesional y sujeto. No se tenía en cuenta el enorme potencial de la relación en sí misma para el desarrollo de las personas. He creído importante volver sobre este tema puesto que hoy el recurso está demonizado al cuestionarse en la profesión que no se puede ser solo gestores de recursos. Pero quienes deseen hacer de su carrera profesional algo más que la pura gestión han de tomar conciencia de la necesidad de la formación permanente para, además de gestionar recursos como instrumento irremplazable que forma parte del proceso de intervención, puedan acompañar a las personas en su desarrollo vital y en su proyecto de hacerse sujetos de poder. Han de ser conscientes las alumnas de que una carrera no agota las posibilidades de conocimiento que han de reunirse para hacer frente a problemas sociales cada vez más complejos.

Y después del recorrido a base de pinceladas por algunos capítulos, que se pueden leer como secuencia o por separado, solo decir que los he ordenado hasta que al final recojo lo que más me ha gustado de mi trabajo, la intervención con grupos. ¿Y por qué lo que más? Porque en ella sí he encontrado la unidad, sí he encontrado ese "espeso caldo sonoro", esa "cooperación rítmica", en palabras de Sennett, para denominar lo que sucede en el quinteto de Brahms; sí he atrapado a veces la unidad en el espíritu del grupo, algo que va más allá de uno mismo, por fortuna. Y, sobre todo, he encontrado la posibilidad de que las personas con las que he trabajado se hayan incorporado a la resolución de sus situaciones problemáticas, al ir construyéndose poco a poco en sujetos reflexivos que poseen el poder de su palabra. Es un trabajo de coral, de concierto; en él confluyen arte y disciplina, en la medida en que el campo de la dinámica de los grupos dispone de una teoría y una técnica bastante formalizada.

E1 libro termina con la palabra de la empatía, con el cuidado de la palabra que nos com- 
promete siempre y que no podemos usar con banalidad. Dicho esto, finalizo esta presentación leyendo los tres últimos párrafos del libro.

Cualquier tema de la vida cotidiana ha de ser tratado con delicadeza, pero más aquellos en los que, incluso detrás de las risas, se percibe el dolor de la pérdida. Y tener claro que somos iguales en lo humano, con la única diferencia del rol, es un ejercicio constante de salud profesional". Y es un valor ético porque, el buen uso del poder, aunque invisible, pertenece a la categoría del respeto al otro, a una conducta profesional que tiene en cuenta la relación en el encuentro con los sujetos.

En el título se alude al poder de la palabra porque la palabra es acción transformadora, la palabra nos involucra, nos compromete y nos induce a cambiar nuestro proceder ante las cosas de la vida cotidiana. Son muchas las experiencias que he acumulado en estos años de trabajo con grupos en las que he podido comprobar todo lo que he traído a estas páginas. Destaco entre otras las siguientes: la fuerza que tienen las conversaciones reflexivas en grupo para modificar nuestras prenociones de la realidad, la fuerza de la palabra en el intercambio grupal para poder construir pensamientos más cercanos a la 'verdad', el estímu- lo para atreverse a pensar y actuar, esto es, para desarrollar nuevas prácticas de conducta.

Y si fuéramos más conscientes del poder de la palabra no diríamos muchas cosas, pero sí diríamos algunas. Como sujetos reflexivos diríamos las más importantes para construir mundos diferentes, mundos sin violencia; crearíamos nuevos vínculos para aunar nuestros esfuerzos en lo que más deseamos hoy casi todas y todos, sin ninguna duda: ser más complementarios para poder cooperar, ser más leales a nuestros deseos; en fin, trataríamos de hacer realidad aquello que fue nuestra aspiración en los sesenta y ocho:

Crear "un hombre (y una mujer) nuevos". Quizás hoy podríamos desarrollar esta idea con más amplios y profundos contenidos, esto es: qué, por qué, para qué y cómo queremos hacer de nuestra persona un individuo trans-formado para una sociedad más justa. Es urgente construir un nuevo pacto sociopolítico.

Muchas gracias a todo el mundo por haberme acompañado en la primera presentación de este libro, seguramente ya el último de mi carrera profesional.

Teresa Zamanillo Peral mtzpgcamino@gmail.com 